Article

\title{
Proactive and Strategic Healthcare Public-Private Partnerships (PPPs) in the Coronavirus (Covid-19) Epoch
}

\author{
David Baxter $^{1}$ and Carter B. Casady ${ }^{2, *(1)}$ \\ 1 Infrastructure Development/PPP Consultant and Steering Committee Member for the World Association of \\ PPP Units \& Professionals (WAPPP), Washington, DC 22312, USA; dbaxter@wappp.org \\ 2 Bartlett School of Construction and Project Management, University College London, \\ London WC1E 7HB, UK \\ * Correspondence: c.casady@ucl.ac.uk
}

Received: 21 May 2020; Accepted: 21 June 2020; Published: 23 June 2020

\begin{abstract}
The coronavirus (COVID-19) pandemic has overwhelmed many national healthcare systems around the world. In attempts to meet their emergency needs and mitigate escalating challenges, governments are increasingly reaching out to the private sector to form sustainable, public-private partnerships (PPPs). Unfortunately, many of these ad hoc efforts have been reactive and uncoordinated to date. This perspective article thus offers a proactive, collaborative, and strategic vision for healthcare PPPs, focusing on short-, medium-, and long-term proposals that will harmonize strategic objectives and mobilize both public and private resources to combat and build resilience against global pandemics like COVID-19.
\end{abstract}

Keywords: public-private partnerships (PPPs); healthcare; coronavirus (COVID-19); resilience; sustainability

\section{Public-Private Partnerships (PPPs) as an Optional Solution?}

Back in 2011, Laurence Carter, former Director of PPP Transaction Advisory at the International Finance Corporation (IFC), gave us an ominous warning about the state of global healthcare provision. He said:

It is impossible to overstate the importance of healthcare-after all, worldwide economic growth and development depend on it—but governments' ability to provide affordable, quality healthcare dwindles every year. The challenge is now to engage private partners to deliver public benefits. Innovative, forward-looking public-private partnerships in healthcare do this, giving businesses an unparalleled opportunity to do well while doing good [1] (p. 1).

As we unwillingly enter into the coronavirus (COVID-19) epoch-which will undeniably be around for the foreseeable future-his words take on new meaning and public-private partnerships (PPPs) are again being globally bandied by political, economic, and healthcare leaders as one of the foremost solutions to mitigating this enduring pandemic - a disease which has crippled economies, infected $\sim 8.5$ million people across 188 countries, and caused over 450,000 deaths worldwide (as of June 18, 2020) [2].

This is especially true in the post-New Public Management (NPM) era where governments are increasingly "engage[d] with a number of private agents in often complex and contractually sophisticated relationships" [3] (p. 150). Given today's pressing need for global collaboration in the increasingly fragmented field of public administration, this perspective article intends to offer a proactive, collaborative, 
and strategic vision for healthcare PPPs aimed at combatting global pandemics like COVID-19 by synthesizing "problems of relevance and rigour" through hybridization-i.e., co-production of knowledge between scholars and practitioners [4] (p. 400). We begin by briefly clarifying what we mean by healthcare PPPs. Then, we outline a set of reactive short-term, proactive medium-term, and long-term, future-proofed recommendations for PPP projects and partnerships between the public and private sectors. We conclude by reflecting on the need to reorganize policy-making processes and adjust existing institutional arrangements in support of proactive and strategic healthcare PPPs.

\section{What Do We Mean by Public-Private Partnerships (PPPs)?}

Listening to the many proponents of these partnerships, it is clear there remains a lack of universal understanding (and consensus) on what is meant by the term 'PPP' [5]. Casady et al. [6] (p. 164), citing Hodge and Greve [3,7], indicate that PPPs may be more accurately described as "five different families of governance arrangements" (see Figure 1).

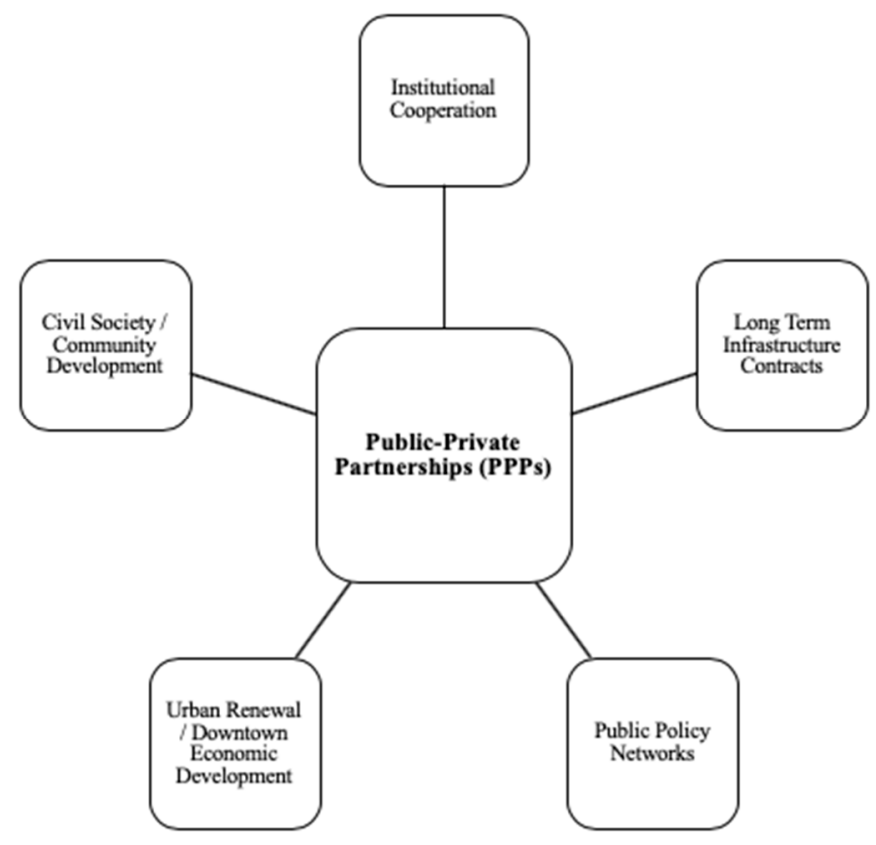

Figure 1. Five families of public-private partnership (PPP) governance arrangements $[3,7]$.

Given this ambiguity around the meaning of PPPs, one must ask:

1. Are we referring to voluntary short-term philanthropic partnerships and alliances between the governments (public sector) and industry (private sector)? or

2. Are we referring to (un)conventional PPPs which involve contractual arrangements between the public and private sectors to provide public works, goods, and services over a defined period of time, in a partnership that improves delivery efficiencies though innovation, risk sharing, and mobilization of joint resources [8-11]?

When it comes to global public health, both philanthropic and (un)conventional PPP approaches have merit, depending on their legal status, disease focus, or sector focus [9]. Cruz and Marques [12] (p. 471) note that governments have often "felt tempted to engage themselves in long-term contracts for the provision and management of health care facilities, under distinct configuration schemes" such as stand-alone infrastructure, clinical services, or other integrated models (see also [13]). Abuzaineh et al. [14] suggest that the three most common PPP business models in healthcare are:

1. infrastructure-based models-i.e., building and/or refurbishing public healthcare infrastructure;

2. discrete Clinical Services models-i.e., adding or expanding clinical service delivery capacity; and 
3. integrated PPP models-i.e., bundled packages of both infrastructure and clinical services.

Because the absence of epidemics is generally regarded as a global public good and "not limited to a specific geographic region or society, but ... spread worldwide" [9] (pp. 123-124), government agencies, non-governmental organizations (NGOs), philanthropic foundations, academic institutions, pharmaceutical companies, and other private enterprises have routinely cooperated using these models to fight public health threats, such as epidemics [15]. This public-private collaboration is essential because the costs (e.g., drugs/vaccine R\&D, hospital/healthcare delivery, medical devices procurement, etc.) associated with global public health are exceptionally high. Private participation thus helps "close that financial gap and furthermore may enhance the outcome quality due to superior technical or scientific skills" [9] (p. 131).

In the COVID-19 epoch, we are already seeing this collaboration play out in real-time. The news is full of stories where corporations like Google, Tesla, and General Motors (GM) are voluntarily offering resources and supplies to immediately buttress breaches in the healthcare sector's defenses. However, these generous activities are regrettably ad hoc at best, geographically limited, and, unfortunately, uncoordinated. Philanthropy will go a long way to serve immediate needs-and should be stepped up wherever possible- but there remains a need for coordinated and strategic initiatives based on cohesive and unambiguous policy. These prioritized actions will ultimately lead to medium- and long-term successes in the battle against the COVID-19 pandemic [16].

\section{A Multifaceted Approach to Healthcare PPPs}

Formal partnerships between the public and private sectors that harmonize the efforts of multiple stakeholders (at international, national, and subnational levels) are thus needed at this critical juncture. However, it will only be possible to mobilize the strengths of both the public and private sectors to mitigate the current failures and challenges we are facing if clear objectives are collaboratively established. If we do this, the implementation of conventional healthcare PPP projects will then be able to support sustainable and resilient healthcare systems that can combat pandemics head on [17].

Unfortunately, we are reminded daily of the multifarious nature of healthcare and the multiple facets that must be addressed to immediately improve its resilience and sustainability. This includes strained supply chains (i.e., protective clothing, medical instruments, pharmaceuticals, etc.), lack of facility capacity (i.e., labs/testing, hospital beds, emergency vehicles, etc.), and shortages in healthcare practitioners (i.e., doctors, nurses, clinicians, support staff, etc.), among others [18]. Current events have proven that most countries' healthcare systems are not resilient due to poor integration. If the resilience of the infrastructure, supplies, and healthcare services is not addressed immediately through sustainable practices, we face an implosive collapse in the face of the current virus' onslaught. What is critically needed are partnerships between the public and private sectors that address short-, medium-, and long-term challenges. We most certainly need to identify long-term corrective strategies that will address future coronavirus pandemics, which many epidemiologists believe could become increasingly common.

\section{Components of a Healthcare PPP Strategy}

Implementers of a PPP-supported recovery strategy should thus consider short, medium, and long-term phases of action. Short-term measures (0-12 months) will naturally be reactive and dynamic while medium-term efforts ( $1-5$ years) will encompass more proactive, formalized strategies for sustainability and resilience. In the long term (5+ years), these initiatives may ultimately expand to transnational settings. Together, these actions need to successively build on enduring partnerships that encourage robust relationships between stakeholders. Moreover, "strong political leadership support for [PPPs], a favorable policy environment, and effective organizational capacity are pre-requisite factors for the successful implementation of [PPPs]" [19] (p. 7). Thus, the longer the required commitment of the PPP, the more formalized the relationship between the public and private sectors needs to be to ensure longevity. Moreover, these partnerships should also have a 'People First PPP' approach 
that harmonizes long-term people-focused healthcare strategies with country-specific Sustainable Development Goals (SDGs) [20].

After addressing immediate short-term needs for PPE, medical devices, healthcare personnel, and flexible surge capacity [21], proposed healthcare PPP programs will need the support of strong regulatory regimes, market reliability, and political and social will to achieve their long-term goals. This will also require strong governance and institutional capacity on the part of government to competitively and transparently procure PPPs that maximize innovation, cost efficiency, value for money, and value for people [11]. In centralized national healthcare systems, partnerships would thus focus on creating healthcare-enabling environments that allow the private sector to serve as a back-up to national healthcare services (e.g., private hospitals being incentivized to seamlessly align with national systems in a time of crises). Conversely, partnerships in decentralized healthcare settings would work to improve the efficiency and equity of resource allocation across systems with different health functions, financing mechanisms, service delivery, human resources, and governance functions. In largely privatized healthcare systems, the focus would also be different. For example, in the USA, private hospitals could be incentivized to align themselves with the Veterans Health Administration, America's largest integrated healthcare system, and the Department of Defense in cases of national emergencies. In all situations, stronger government-led relationships supported by private sector innovators need to be established between users of services and consumers of supplies, whether they are private, decentralized, or national healthcare systems.

\section{Short-Term, Reactive PPP Projects and Partnerships (0 to 12 Months)}

As the COVID-19 pandemic accelerates, these initial partnerships are likely to be reactive in nature to constantly emerging needs, relying on the cooperative goodwill of both the public and private sector. Activities associated with this reactive stage may include:

1. encouraging informal philanthropic partnerships between the public and private sectors to bridge pressing needs;

2. improving supply chains through incentives from the public sector (i.e., National Health Authorities) that avoid unnecessary cost escalations for needed products;

3. promoting collaborative actions where national and subnational government agencies identify and mobilize resources (e.g., pharmaceuticals, medical instruments, PPE, etc.) according to shifting locational needs;

4. bolstering access to digital infrastructure that allows healthcare stakeholders to be fleetfooted in their decision making and responsiveness;

5. creating healthcare data systems that collect information on how the pandemic spreads as well as "lessons learned" for future events;

6. incentivizing private sector-led solutions that are non-proprietary/open source; and

7. relaxing unnecessary bureaucratic red tape that hinders meaningful sector partnerships.

Naturally, many of these activities may offer governments the ability to "[internalize] transactions, [minimize] legalisms involved in complex contractual negotiations with external actors, and [provide] a more stable framework for bargaining" [22] (p. 31). However, the dynamic nature of this reactive stage in the pandemic also presents governments with a unique opportunity to deploy PPPs that will:

break the public-sector monopoly, inject ... flexibility into provision of [healthcare services], extend the public sector's access to technical, financial, and physical resources, and improve service quality, all while operating in increasingly uncertain policy environments [6] (p. 162).

\section{Medium-Term, Proactive PPP Projects and Partnerships (1 to 5 Years)}

Once a clearer picture of this pandemic's extent and magnitude is established, PPP strategies should then move away from being singularly reactive to proactive. These proactive PPPs should 
focus on product development, public education/advocacy, quality assurance, global coordination, improving health access, and strengthening clinical services, among other tasks [23]. Moreover, proactive strategies should have a goal of implementing partnerships that are increasingly formalized and sustainable for improved resilience. As a result, activities in the medium term may include:

1. improving health risk detection infrastructure at airports through agreements with private sector airport concessionaires and government health agencies, which would monitor future outbreaks as soon as they occur;

This will require the international collaboration of large air carriers.

2. identifying existing (i.e., brownfield) PPP project sites that can be repurposed for the ongoing battle against COVID-19 in case it does assume a repetitive annual cycle that many epidemiologists fear;

This includes repurposing existing facilities, as well as expanding them through design, build, and financing PPP agreements. For example, in partnerships between the healthcare and hospitality sectors, hotels adjacent to existing and future hospitals could be repurposed or built to certain specifications and serve as auxiliary units in a future crisis. In many places around the world, medical tourism and university medical school facilities exist that could serve as a second line of defense. For instance, the Mayo Clinic Marriot Hotel in Rochester, Minnesota was purposefully built to provide seamless accommodation for hospital patients from all over the world.

3. exploring binding agreements between suppliers and consumers of medical equipment/goods to build medical stockpiles in joint venture government-private sector warehouses;

These surplus storage facilities would be joint ventures between national healthcare institutions (i.e., health ministries, Departments of Defense, state governments, etc.) and the private sector and could be launched as PPP projects. Medical supplies would be stored and circulated from these facilities as needed once a strategic supply threshold is reached. In the medium term, these warehouses would also begin as regional centers before expanding to subnational locations in the long term.

4. rewarding/incentivizing innovative national producers of medical goods to maintain a dormant production capacity that can be mobilized as soon as the need arises.

This last point would include developing collaborative, harmonized, and cohesive research and development (R\&D) PPP programs where the private sector is incentivized by government to become a long-term partner. Healthcare solutions and remedies (e.g., vaccines) discovered through these partnerships would ultimately supply generic remedies that could be duplicated by all competent and collaborating pharmaceutic suppliers without fear of copyright infringements.

In total, a variety of these medium-term healthcare projects will have to be more traditional PPPs in order to be effective. Although many governments have already established comprehensive policies, operational frameworks, and legislative authorization for such projects, new procedural and process-related guidelines may still be needed in certain jurisdictions to facilitate private collaboration (e.g., USA) [24,25]. Nevertheless, these projects should serve as the basis of a sustainable, long-term approach that supports a resilient healthcare system at a national and international level.

\section{Long-Term, Future-Proofed PPP Projects and Partnerships (5+ Years)}

Finally, because pandemics do not recognize borders and health is a global public good, long-term transnational strategies must be adopted in this last phase. These strategies should include the implementation of transnational PPPs or global PPPs (GPPPs) that can operate without government restrictions [9]. Such borderless GPPPs must be formalized, sustainable, collaborative, and resilient. Likewise, there should also be a focus on identifying projects that are future-proofed for global implementation [25]. 
Naturally, implementing long-term PPP programs to prevent global pandemics like COVID-19 will require input from a host of stakeholders, including but not limited to:

1. all (if possible) national government health ministries;

2. the World Health Organization (WHO);

3. NATO and its equivalents;

4. the International Red Cross/Crescent;

5. aid organizations (e.g., USAID, JICA, etc.);

6. multilateral development banks; and

7. regional associations like the European Union (EU).

Although these stakeholders will also be involved in the earlier phases as well, long-term GPPPs will require greater interorganizational networking and coordination. For instance, national health priorities "should complement and not duplicate state initiatives and should be optimally integrated with national health systems without any conflict of interest" [24] (p. 5). Once governments identify these national initiatives, they should harmonize them with regional priorities. Collectively, these regional priorities should then be harmonized into a global agreement/mandate. Such an international mobilization and commitment will require selflessness among nations and collaboration that has never been seen before to combat global pandemics. By building consensus around a strategic global framework for pandemic prevention, long-term GPPP programs could then be deployed by global healthcare organizations. National healthcare PPP programs would continue to be implemented by countries themselves, but they could be supplemented and coordinated by international agreements when needed. Once guided by a coordinated and cohesive global action plan, all medium-term strategic measures could then be revised and fine-tuned into long-term solutions. For example, new infrastructure projects (i.e., greenfield PPPs) could supplement mature existing facilities (i.e., brownfield PPPs) to build out capacity in the ongoing battle against future pandemics. Likewise, joint venture storage facilities holding international medical stockpiles could be expanded from regional to subnational locations, connected by integrated transportation hubs, and used as flex/redundant capacity in global supply chains. Moreover, international bodies like the WHO should assume governance responsibilities for 'how' and 'when' dormant production capacity/resources are internationally mobilized to mitigate the effects of a pandemic like COVID-19. To date, the WHO has already developed draft interim guidance on a 'whole-of-government' and 'whole-of-society' response to the COVID-19 pandemic that includes three tiers of private sector engagement and mobilization [26]. Naturally, these formalized approaches will ensure nations do not hoard or monopolize resources, build redundancy into existing healthcare services, and increase the resilience of global healthcare systems/networks.

\section{Conclusions}

Although these short-, medium-, and long-term measures might seem utopian, the world as a whole needs to ask whether it can ignore the need for global strategies to combat truly global pandemics in the future. The increasing globalization of the private sector might compel national governments to think progressively about the need for and value of global healthcare PPPs. However, government should also not be "transfixed by the PPP ideal" [27] (p. 1109). In reality, PPPs are not a panacea for all of the shortcomings associated with traditional healthcare delivery and pandemic preparedness. After all, government relationships with the private sector are not self-administering; "they require, rather, aggressive management by a strong, competent government" [28] (p. 6). In this light, we must reflect on the need "to reorganize policy-making processes and to adjust existing institutional structures" [29] (p. 197). More importantly, we must not lose focus on the fact that this healthcare pandemic needs solutions that are not only economic in nature, but also humanely focused on society at large. In the end, we are all in this together. 
Author Contributions: The authors confirm contribution to the paper as follows: conceptualization (D.B. and C.B.C.); writing-original draft preparation (D.B.); writing-review and editing (C.B.C.). All authors have read and agreed to the published version of the manuscript.

Funding: Article processing charges (APCs) for open access publication were covered by UCL's Open Access Team. No other external funding was received for this research.

Conflicts of Interest: The authors declare no conflict of interest.

\section{References}

1. International Finance Corporation (IFC). Health PPPs. Handshake IFC's Q. J. Public Priv. Partnersh. 2011, 3, $1-75$.

2. John Hopkins University (JHU). COVID-19 Dashboard; Center for Systems Science and Engineering (CSSE), JHU: Baltimore, MD, USA, 2020.

3. Hodge, G.; Carsten, G. Public-private partnerships: Governance scheme or language game? Aust. J. Public Adm. 2010, 69, S8-S22. [CrossRef]

4. Harty, C.; Roine, L. The futures of construction management research. Constr. Manag. Econ. 2017, 35, $392-403$. [CrossRef]

5. Marsilio, M.; Giulia, C.; Corrado, C. The intellectual structure of research into PPPS: A bibliometric analysis. Public Manag. Rev. 2011, 13, 763-782. [CrossRef]

6. Casady, C.B.; Kent, E.; Raymond, E.L.; Richard Scott, W. (Re)Defining Public-Private Partnerships (PPPs) in the New Public Governance (NPG) Paradigm: An Institutional Maturity Perspective. Public Manag. Rev. 2020, 22, 161-183. [CrossRef]

7. Hodge, G.A.; Carsten, G. Public-Private Partnerships: An International Performance Review. Public Adm. Rev. 2007, 67, 545-558. [CrossRef]

8. Organization for Economic Cooperation \& Development (OECD). Recommendation of the Council on Principles for Public Governance of Public-Private Partnerships; OECD: Paris, France, 2012.

9. Schomaker, R.M. Public-private governance regimes in the global sphere. Public Organ. Rev. 2017, 17, 121-138. [CrossRef]

10. Casady, C.B.; Kent, E.; Raymond, E.L.; Richard Scott, W. Examining the State of Public-Private Partnership (PPP) Institutionalization in the United States. Eng. Proj. Organ. J. 2018, 8, 177-198.

11. Casady, C.B. Examining the Institutional Drivers of Public-Private Partnership (PPP) Market Performance: A Fuzzy Set Qualitative Comparative Analysis (fsQCA). Public Manag. Rev. 2020. [CrossRef]

12. Cruz, C.O.; Rui, C.M. Integrating infrastructure and clinical management in PPPs for health care. J. Manag. Eng. 2013, 29, 471-481. [CrossRef]

13. Abdel Aziz, A.; Shu, W. PPPs for Healthcare Facilities in British Columbia: A Preliminary Analysis. In Proceedings of the ASCE Construction Research Congress, Tempe, AZ, USA, 8-10 March 2020.

14. Abuzaineh, N.; Brashers, E.; Foong, S.; Feachem, R.; da Rita, P. PPPs in Healthcare: Models, Lessons and Trends for the Future. Healthcare Public Private Partnership Series, No. 4; The Global Health Group, Institute for Global Health Sciences, University of California, San Francisco and PwC: San Francisco, CA, USA, 2018.

15. Buse, K.; Andrew, M.H. Seven habits of highly effective global public-private health partnerships: Practice and potential. Soc. Sci. Med. 2007, 64, 259-271. [CrossRef] [PubMed]

16. Baxter, D. How Will Coronavirus Affect Public-Private Partnerships? World Bank Blogs: Washington, DC, USA, 2020.

17. Baxter, D. The Need for Sustainable PPP Recovery Strategies in a Post-COVID-19 World; LinkedIn: Sunnyvale, CA, USA, 2020.

18. Ranney, M.L.; Valerie, G.; Ashish, K.J. Critical supply shortages-The need for ventilators and personal protective equipment during the Covid-19 pandemic. N. Engl. J. Med. 2020, 382, e41. [CrossRef] [PubMed]

19. Opara, M.; Fathi, E.; Oliver, O.; Hussein, W. Effects of the Institutional Environment on Public-Private Partnership (P3) Projects: Evidence from Canada. Account. Forum 2017, 41, 77-95. [CrossRef]

20. United Nations Economic Commission for Europe (UNECE). What Are People-First PPPs? UNECE International Center of Excellence: Geneva, Switzerland, 2019.

21. Khorram-Manesh, A. Flexible surge capacity-public health, public education, and disaster management. Health Promot. Perspect. 2020, 10, 1-5. 
22. Salamon, L. The New Governance and the Tools of Public Action: An Introduction. In The Tools of Government: A Guide to the New Governance; Salamon, L., Elliot, O.V., Eds.; Oxford University Press: New York, NY, USA, 2002; pp. 1-48.

23. Nishtar, S. Public-private 'partnerships' in health-A global call to action. Health Res. Policy Syst. $2004,2,5$. [CrossRef] [PubMed]

24. Albalate, D.; Germà, B.; Richard Geddes, R. Do Public-Private-Partnership-Enabling Laws Increase Private Investment in Transportation Infrastructure? J. Law Econ. 2020, 63, 43-70. [CrossRef]

25. Baxter, D. Future-Proofing Resilient PPPs; World Bank Blogs: Washington, DC, USA, 2017.

26. Hanlon, B.O.; Mark, H.; Cynthia, E.; David, C. An Action Plan to Engage the Private Sector in the Response to COVID-19; Interim Guidance; World Health Organization (WHO): Geneva, Switzerland, 2020.

27. Hodge, G.; Carsten, G.; Mhamed, B. Do PPP's work? What and how have we been learning so far? Public Manag. Rev. 2018, 20, 1105-1121. [CrossRef]

28. Kettl, D.F. Sharing Power: Public Governance and Private Markets; Brookings Institution Press: Washington, DC, USA, 2011.

29. Teisman, G.R.; Erik-Hans, K. Partnership arrangements: Governmental rhetoric or governance scheme? Public Adm. Rev. 2002, 62, 197-205. [CrossRef]

(C) 2020 by the authors. Licensee MDPI, Basel, Switzerland. This article is an open access article distributed under the terms and conditions of the Creative Commons Attribution (CC BY) license (http://creativecommons.org/licenses/by/4.0/). 